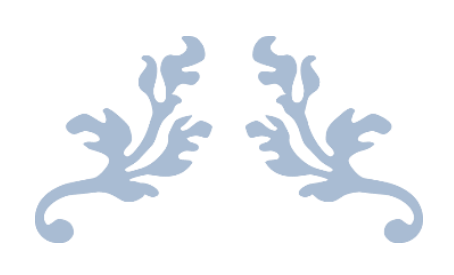

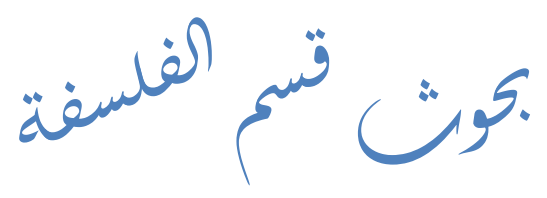

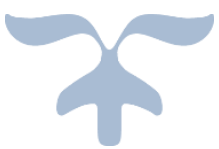




\section{الفلسفة والمرأة عند كل من أفلاطون ومل}

الباحثة /علا سيد محمد عبدالديم

$$
\text { إشراف }
$$

د/ فاطمة يونس

مدرس الفلسفة الحديثة
أد/ مزة السروى

أستاذ الفلسفة اليونانية

الملخص:

إن قضية المرأة من القضايا التي شغلت العالم منذ القدم، فهي دائما تكون الآخر بالنسبة

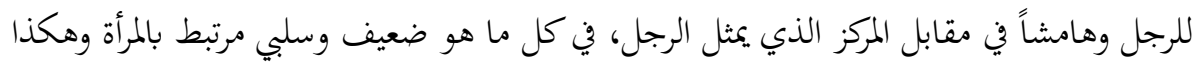

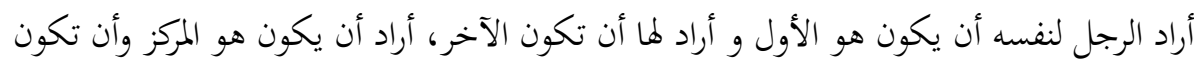

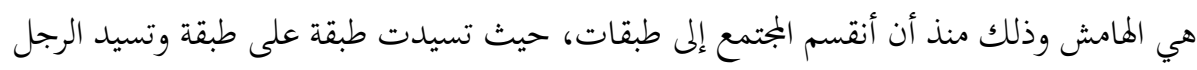
على المرأة.

وتتناول هذه الدراسة موضوع الفلسفة والمرأة في تاريخ كل من أفلاطون وجون ستيوارت

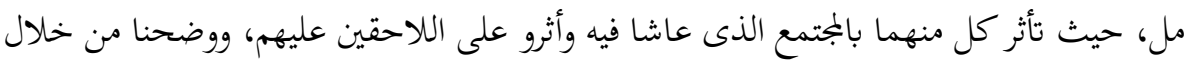

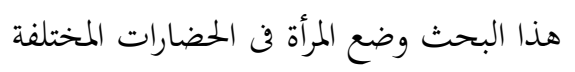

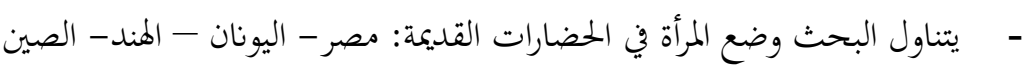

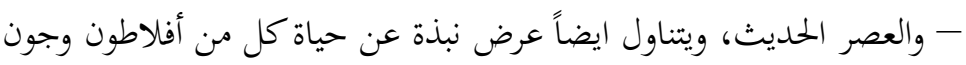

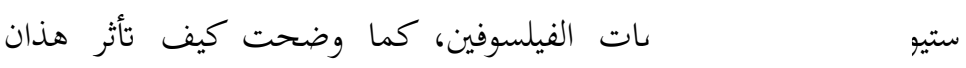

الفيل

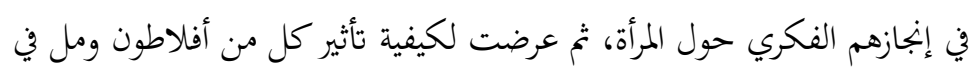

اللاحقين عليهما.

ملخص البحث بالانجليزى:

The issue of women is one of the issues that has occupied the world since ancient times, as it is always the other 
for the man and a margin in contrast to the position that represents the man, in everything that is weak and negative related to the woman, and this is how the man wanted himself to be the first and wanted her to be. The other, he wanted it to be the center and to be the margin, since society was divided into classes, where one class dominated one class and the man dominated the woman.

This study deals with the subject of philosophy and women in the history of both Plato and John Stuart Mill, as each of them was affected by the society in which they lived and influenced those who followed them, and we explained through this research the status of women in different civilizations

The research deals with the status of women in ancient civilizations: Egypt, Greece, India, China, and the modern era. They were the reason for their intellectual achievement about women, and then I presented how each of Plato and Mel affected them in the following.

إن قضية المرأة من القضايا التي شغلت العالم منذ القدم، فهي دائما تكون الآخر بالنسبة

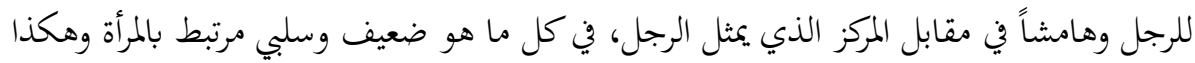

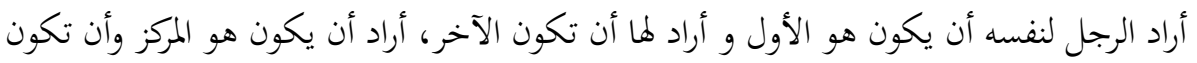

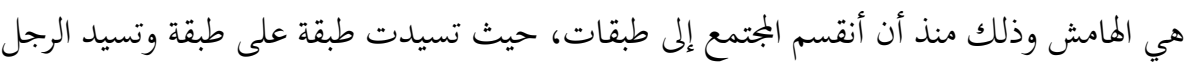

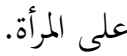

كانت بداية العصور البدائية هي التي حددت وضع المرأة، فقد كانت مهمة المرأة في تلك الك الكانك

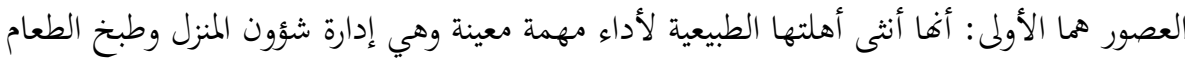

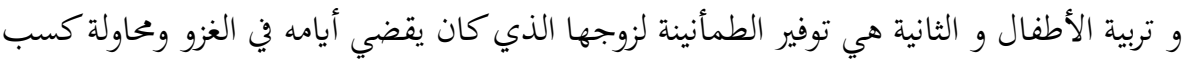


العيش عن طريق الغارات والخوض في المعارك، وكان لهذين العاملين أثر في وضع منهج معين لوضع المرأة.

وتتناول هذه الدراسة موضوع الفلسفة والمرأة في تاريخ كل من أفلاطون وجون ستيوارت

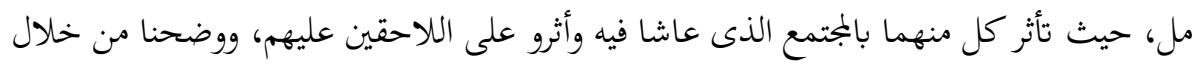

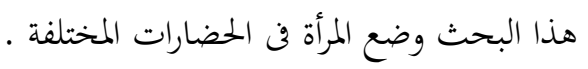
أن تمميش المرأة دائما و حصرها في الأدوار الثانوية، أدى إلى قلة الثقة في قدراتها العقلية

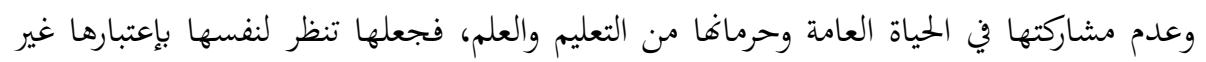

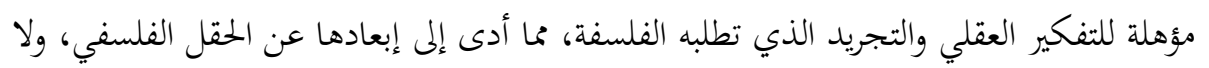
ترى نفسها إلا مع رجل تطيعه ويتصرف بها كيفما يشاء .

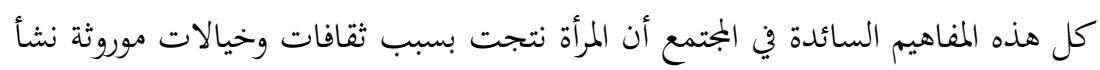
الرجل عليها ولا يقدر على استيعاب غيرها، فدائما العادات والتقاليد الموروثة يصعب تغيرها تغيراً

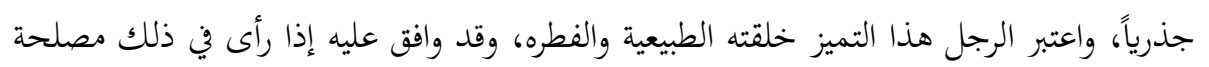
له

أما عن موقف جون ستيوارت مل مثلما أشرت سابقاً، أن المجتمع الأوروبي لا يختلف تاريخه

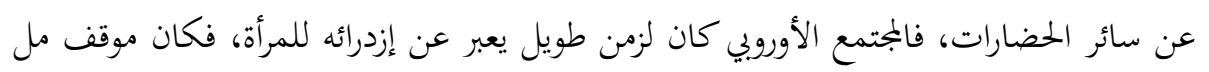

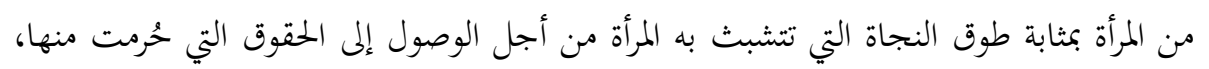

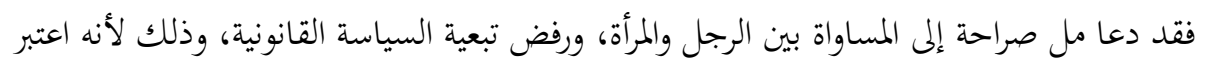
تبعيتها انتهاكاً لحريتها.

حقيقة لم يكن في مقدور المرأة أن تكون حرة في تصرفاتما في التاريخ البشر كله، ففي الحضارة

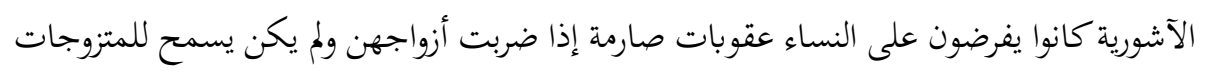
أن يخرجن إلى الطريق العام بغير حجاب، ونشهد في كثير من نواحي الحياة الآشورية صرامة أبويه. (1) ول ديورانت : قصه الحضارة، الجلد الاول ، الباب العاشر ، الفصل الثاني، ترجمة زكي نجيب محمود، محمد بدران ،

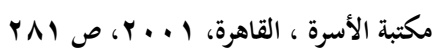


أما في الحضارة الهندية فقد كانت أيضا الأسرة الهندية من الطراز الأبوي الصميم، فالوالد هوالسيد الكامل السيادة على الزوجة والأبناء، وقد نص التشريع على أن المرأة طول حياتها ينبغي

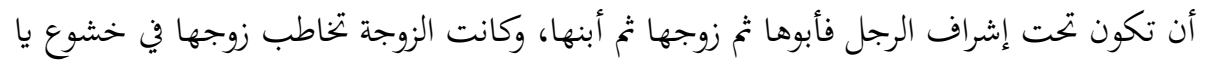

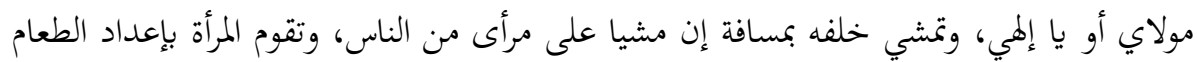

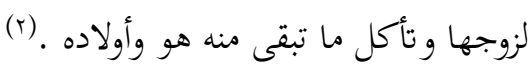
وكذلك في الحضارة الصينية فقد كان الآباء يدعون في صلاقمى أن يرزقوا أبناء، وكانت البنات

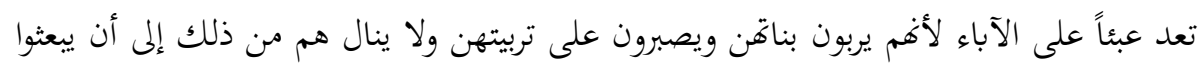

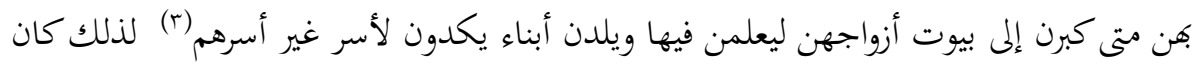

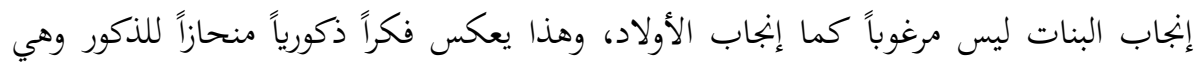
تناقض مع العدالة المرجوة. وكانت المرأة في الحضارة الإغريقية مسلوبة الإرادة والحرية، فتقوم المرأة بكل أعمال المنزل من

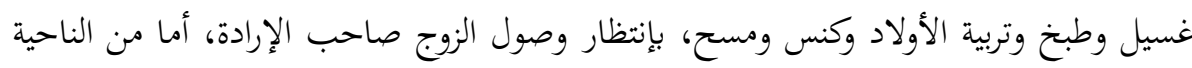

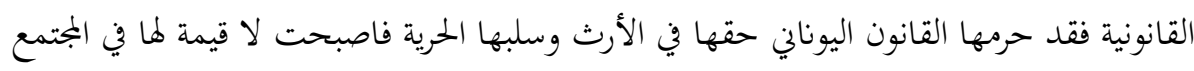

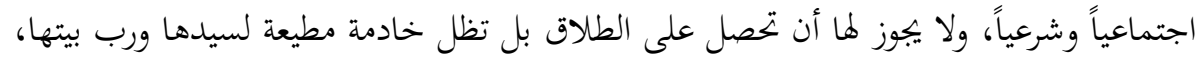

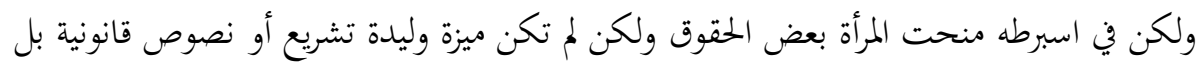

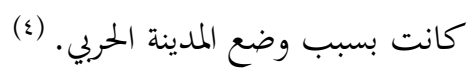
والمرأة الرومانية على الرغم من حصولها على بعض حريتها في القانون الروماني إلا أها كانت

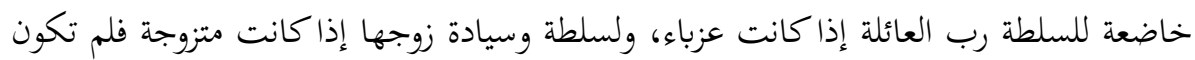

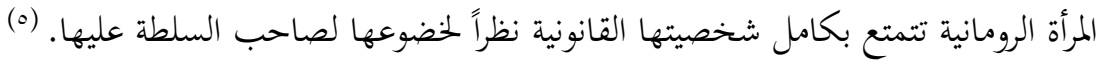
فتعرضت المرأة لظم وقهر شديد على مدار التاريخ البشري كما أشرنا سابقاً باستثناء فترة

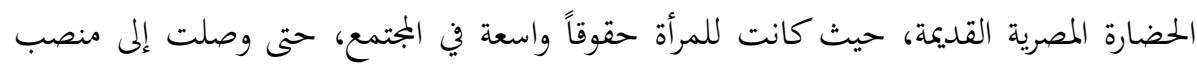

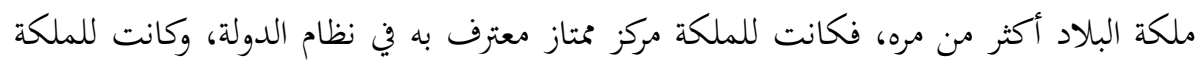

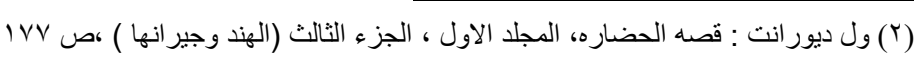

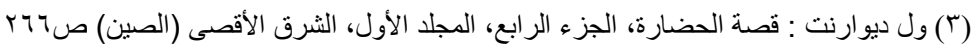

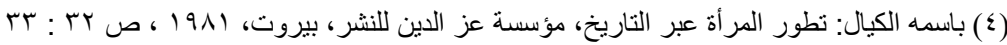

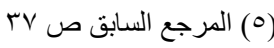


نفوذاً كبيراً في عصر الدولة القديمة، وقد إعتلت العرش نساء كثيرات تمثلت فيهن البطولة النادرة و المقدرة الفذة، فنذكر منهن الملكات الشهيرات اللاتي لعبن أدوارمهمة في التاريخ المصري القديم وخلدت أسماؤهن في سجل الخالدات، ومنهن حتب حرس، وخنت كاوس، وتويا، وأياح حتب،

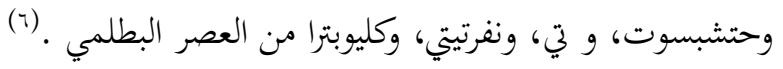
فقد ظلت الحضارة المصرية تتمتع بكامل حريتها طيلة العصر الفرعوني، فعندما قدم هيردوت إلى مصر في القرن الخامس قبل الميلاد أدهشته حياة التحرر والاختلاط التي تحياها المرأة المصرية،

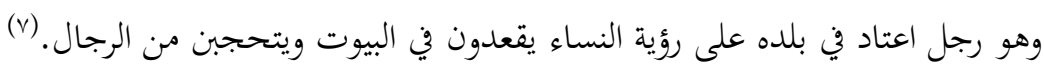
يقول ماركس ملر " ليس ثمة شعب قديم أو حديث قد رفع منزلة المرأة مثل ما رفعها سكان وادي النيل" فالنقوش تصور النساء يأكلن ويشربن بين الناس، ويخرجن بدون رقيب و يمارسن الأعمال الصناعية والتجارية بكامل حريتهن . (^) ولكن بسبب أثر التقاليد الأبوية التي أدخلها الهكسوس وأثر انتقال البلاد من عزلتها الزراعية

من حال السلم إلى طور الاستعمار والحرب أدى إلى نقوص سلطان المرأة على مر الزمان.(9) سرعان ما تدهور حالها بعد اهيار الحضارة المصرية، لقد كان حالها في عصر اليونان، وطوال العصور الوسطى سيئا، غير أها وإن كانت قد أخذت بعض الحريات وبعض الحقوق في عصر الحضارة الأوروبية الحديثة إلا أها ما زالت تعاني في مجتمعاتنا الشرقية تعاني حتى في وقتنا هذا من التخلف والظلم الاجتماعي سواء من الرجل أو من العادات والتقاليد السائدة في المجتمع، فيجب النظر للمرأة باعتبارها نصف المجتمع فهي الأم والزوجة والأبنه، ولا يجب اعتبار المرأة سلعه تباع وتشترى مثلما كان في السابق، وأن نفوذ المرأة واعطائها حقوقها ذلك لا يعني الحط من شأن الرجال

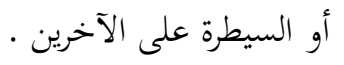

(1) وليد نظير : المر أة في تاريخ مصر القديم، تقديم د. يا هور لبيب ،م.د محمد حماد : وكالة الصحافة

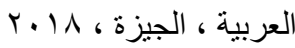

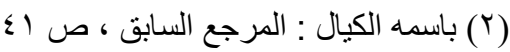
(r) ول ديور انت : قصة الحضارة ، المجلد الاول ، نرجمة زكي نجيب محمود ومحمد بدران مكتبة

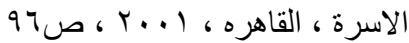

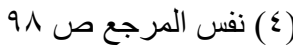


تأثر أفلاطون بثقافة عصره

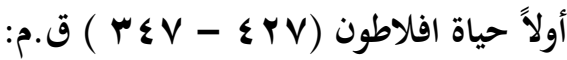

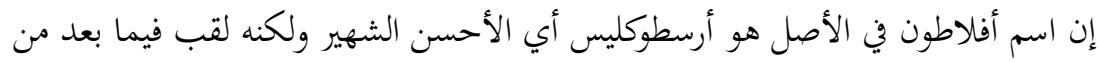

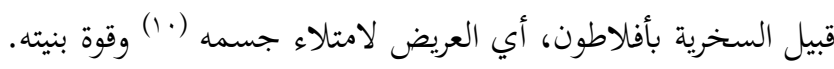

ويتسب أفلاطون إلى أسرة ارستقراطيه عريقة و هو ابن اريستون و بروكيتوني، ولد في أثنينا

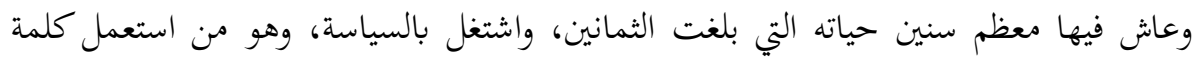

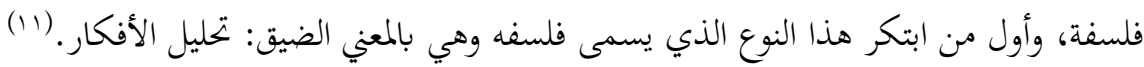

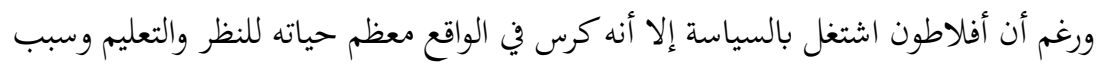

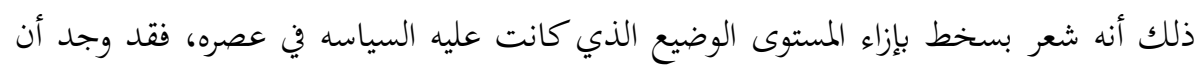

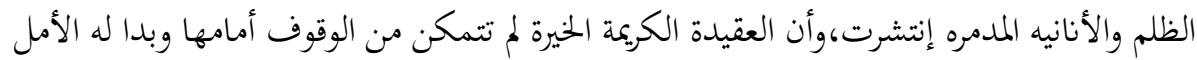

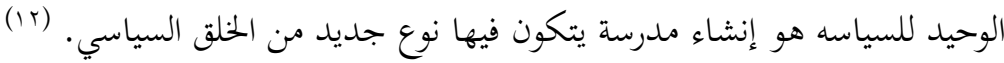

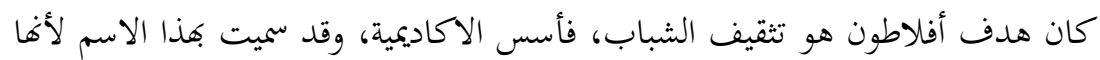

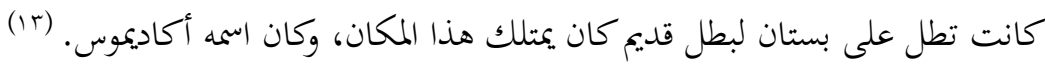

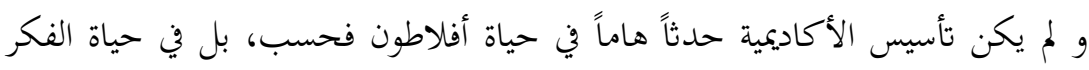
الغربى كله، حيث ظلت قائمة حوالى ما يقرب من عشر قرون حتى أمر الإمبراطور الرومانى جستنيان

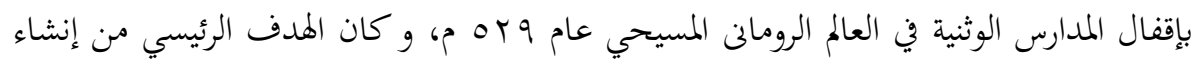

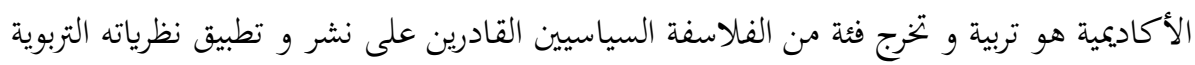

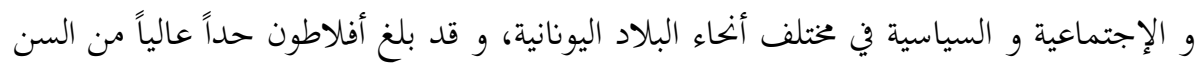

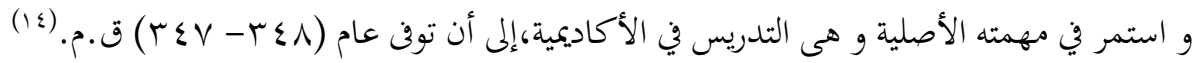

( ) أحمد شمس الدين ، افلاطون ( سبرته و فلسفته ) ، دار الكتب العلمية ، لبنان • 199 ، صـ

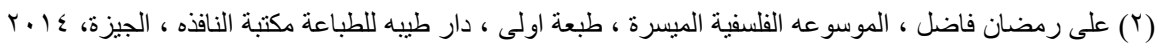
ص ص

(r) الموسو عة الفلسفة المختصرة ، نقلها على الانجليزية فؤاد كامل ، وجلال العشري و عبد الرشيد الصادق ، راجعها

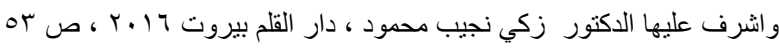

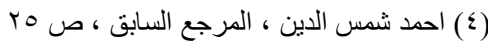
(0) نفس المرجع صنr-r 
ألف أفلاطون في الأكاديمية دروسه و محاوراته و ترك لنا عدداً كبيراً من المحاورات فهو من

بين الفلاسفة القدماء أول فيلسوف تظل أعماله محفوظة دون أن تسطو عليها الضياع. (10)

\section{ثانيا مؤلفاته:}

توجد بإسم أفلاطون ست و ثلاثون محاورة بعضها مشكوك في صدق نسبتها إليه و يمكن

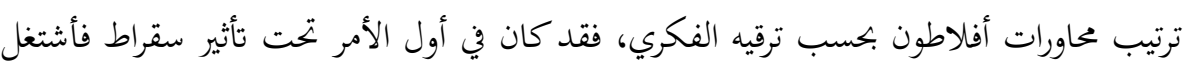
بمسائل الأدب و كتب خلال تلك الفقرة أتريفون و منيون و احتجاج سقراط على أثلينا فئا (الدفاع) و كريتون و بروتاغوراس و جورجياس . (1) وفي الفترة الثانية كتب محاورات نصيبها من النظريات الفكرية أكثر من نصيب الأولى، وهي ثياتيتوس و السوفطائي وفيلبوس وبارميندس و كراتيلوس والسياسي.

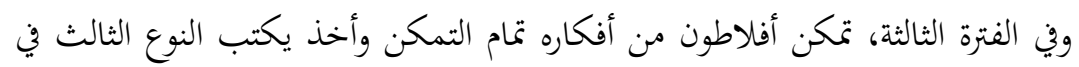

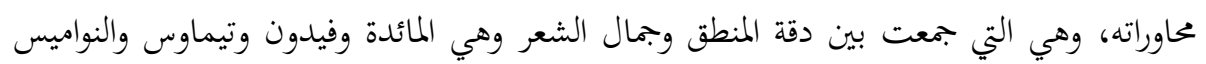
والجمهورية أو السياسة المدنية. (1V) ثالثاً: فلسفة أفلاطون: هناك من يقول أن افلاطون هو الفلسفه اليونانية كلها، إذ تلتقي فيه عناصرها الأساسيه

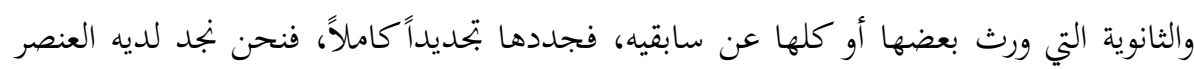

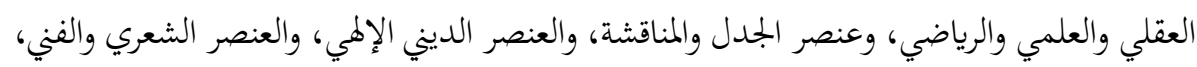

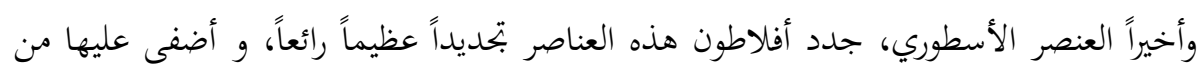
أصالته وعبقريته، مما جعل منها فلسفة تطاول الزمن وتنازع الخلود.

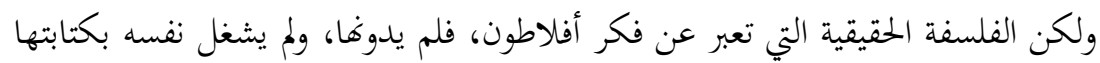

$$
\text { وإنما وصلت إلينا عن طريق بعض تلاميذه في الأكاديميه ولاسيما أرسطو . }
$$

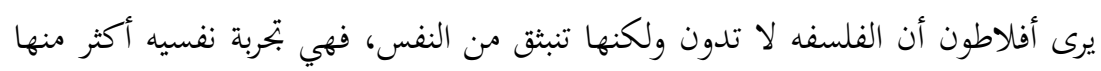

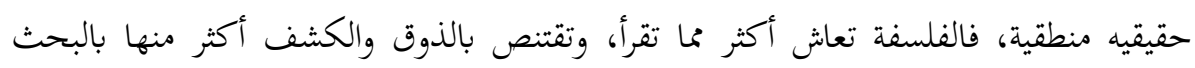

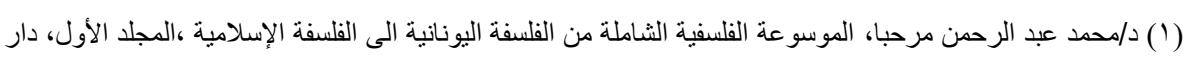

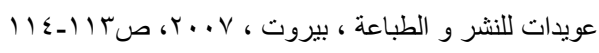

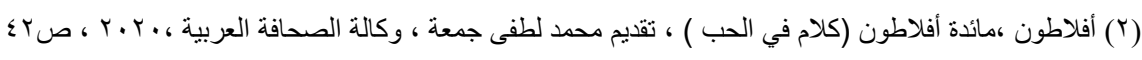

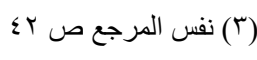


والنظر، وكل من ذاق عرف، فالفلسفة إذاً هي البصر بالخير و الحق و الجمال، وهي ضرب من

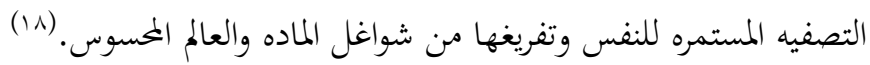

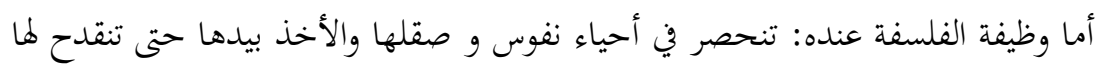

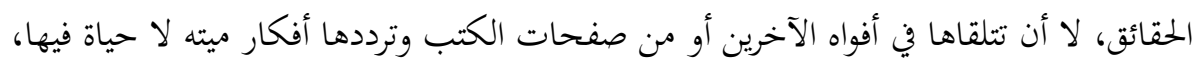

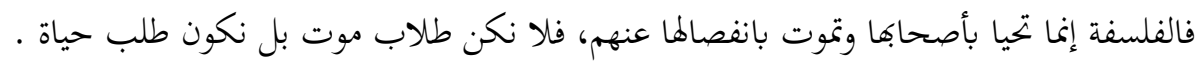

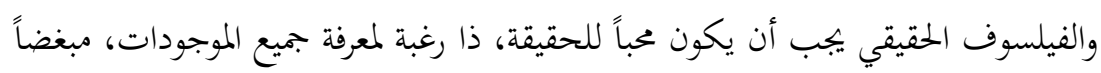
للكذب محباً للصدق، ميالاً إلى احتقار الذات الجسدية، غير مكترث بالمبال بلمال، زاهداً في الحياة، نابذاً

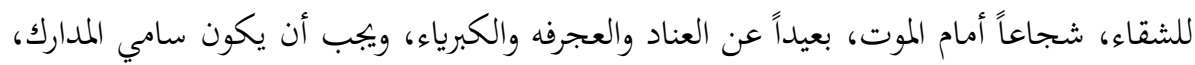

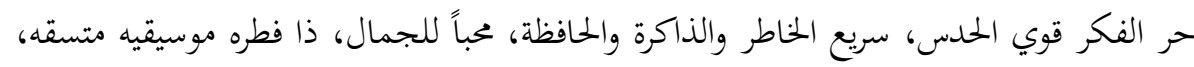

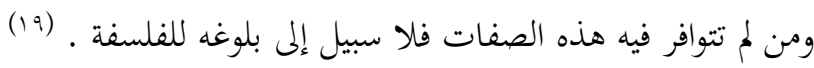
رابعاً: تأثر أفلاطون بثقافة عصره:

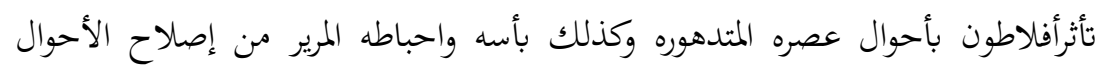

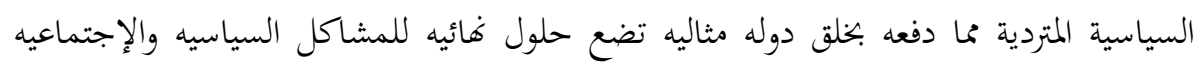
والإقتصاديه، فمرت أثينا في العصر الذي عاش فيه أفلاطون بظروف سياسيه وإقتصاديه عصيبة ؛

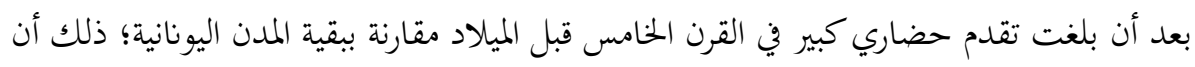

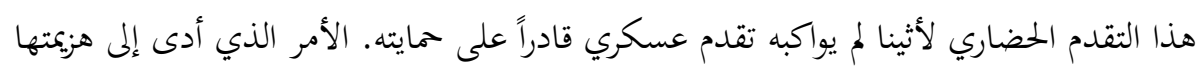

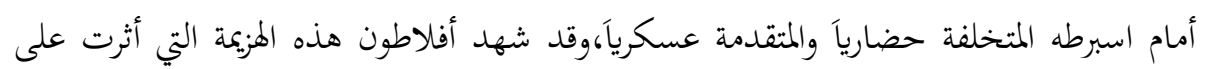

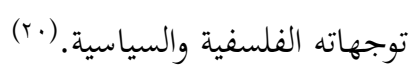

وقد استفاد أفلاطون من النظام الاسبرطي في مدينته الفاضلة، وقد تأثر أفلاطون بمختلف الفيه

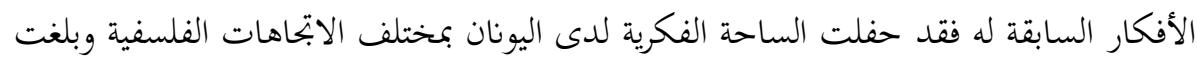

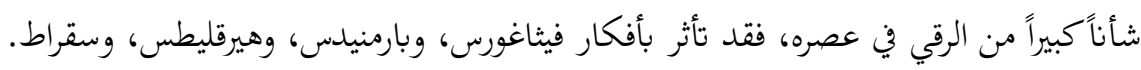

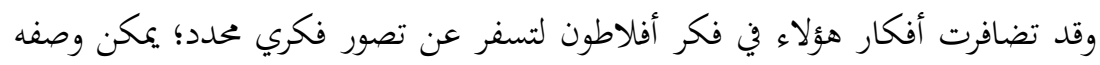

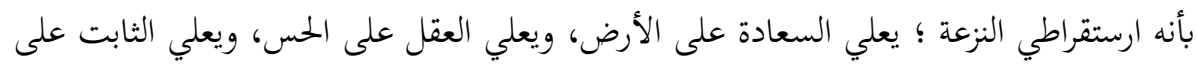

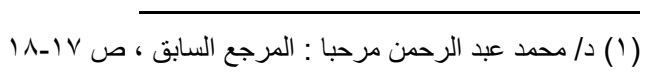

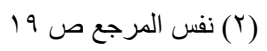

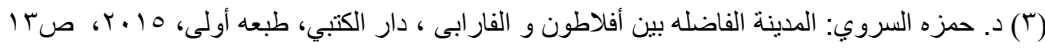


المتغير، ويعلي الخير على بقيت الفضائل، ويعلي الفلسفة على بقية المعارف، ويعلي الفيلسوف على بقية البشر، ويعلي النفس على الجسد، ويعلي النفس العاقلة على النفس الغضبية والنفس الشهوانية، و بإختصار لقد كرس أفلاطون الثنائية على الفكر وأدى تطبيق ذلك على الواقع إلى تصور مدينة فاضله أقرب ما تكون إلى النموذج السماوى؛ فيها أقل قدر من التغير وأكبر قدر من الكمال والثبات. (r) (r)

فقد كانت المرأة في الحياة اليونانية عموماً والأثينيه خصوصاً دور مزدوج فهي المحافظة التقليدية القابعه داخل بيتها الراعيه لشئون منزلها وهي الزوجه والمرأة الجريئة المتحررة من كل التقاليد إذا ما اختارت أن تلعب دور الغائية العاشقة للرجال خارج بيوهم. (rr) كان موقف أفلاطون من المرأة نتيجة تأثره بالمجتمع اليوناني الذي كان يحتقر المرأة و يجعلها متدنيه، فقد كانت نظرة الفلاسفة في عصره إليها نظره دونيه تعكس نظرة المجتمع اليوناني والأثيني خصوصاً، فقد حاربها ديمقريطس واعتبر أن المرأة معطلة للفلسفة والتفلسف مما دعاه إلى عدم الزواج والتحذير منه، فممارسة الشهوة تغيب عقل المرء تعطل الفلسفه. وكان رأي انطيفون السوفسطائي يقول: عندما يتزوج الرجل بامرأة فتتحول حياته إلى صراع ونزاع، فالزواج عنده تنازع كبير بين الناس. فقد يظن الرجل أن يسعى للسعادة بامتلاك المرأة فإذا به يجلب لنفسه الشقاء. (r (r) وقد تأثر أفلاطون بأستاذه سقراط، فكان يرى سقراط أن وجود امرأة هي مصدر الأزمة والاغيار في العالم، وقد شبه المرأة بالشجرة المسمومة التي يكون ظاهرها جميلاً، ولكن العصافير تموت عندما تأكل منها، وكان مفهوم الإنسان عند سقراط لا ينطبق إلا على الرجل الأثنيني الحر، (ء؟) تلك كانت صورة المرأة في عصر أفلاطون.

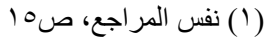

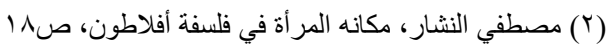

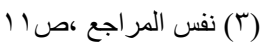
( ) المرأة العربيه والفكر الحديث،مفيد محمد ابراهيم، دار مجدلاوي للنشر والتوزيع، طبعه أولى، عمان، ه . . ب،ص7م 
لقد تأثر تاريخ المرأة في أوروبا بأفلاطون الذي يمثل المجتمع اليوناني، فالمجتمع الأوربي كان

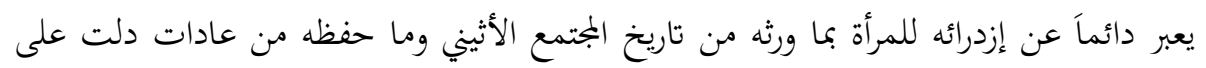

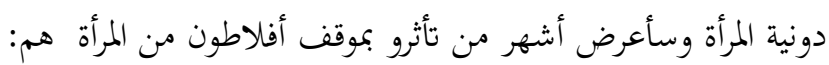

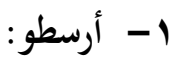

كانت فلسفه أرسطو عن المرأة تقنين لما قاله أفلاطون، وكان يتكلم بلسان حال التقاليد

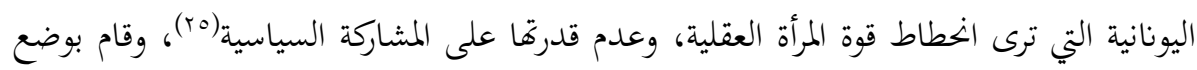

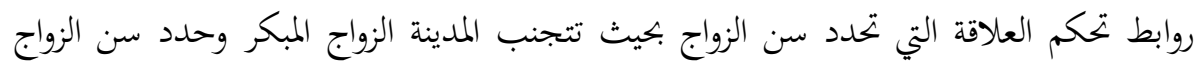

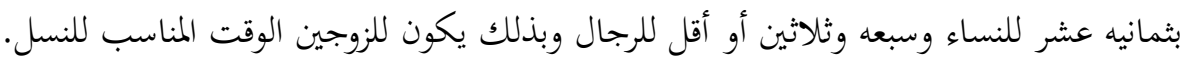

يجب أن يكون الزواج عند أرسطو تحت إشراف الدوله وذلك لضمان سلامه النسل وأيضاً

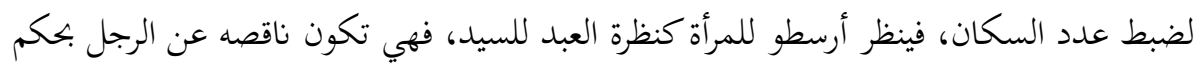

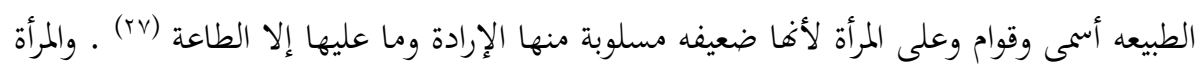
في رأي أرسطو تعرف بوظيفتها البيولوجية (الإنجابية)،وواجبتها داخل المنزل.

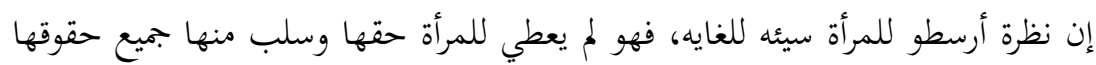

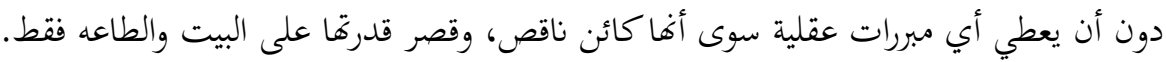

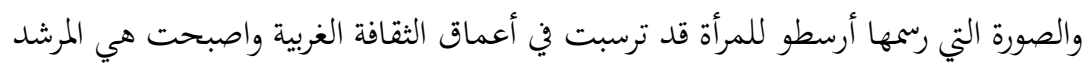

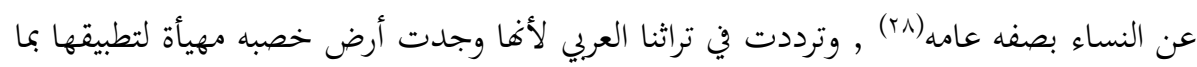

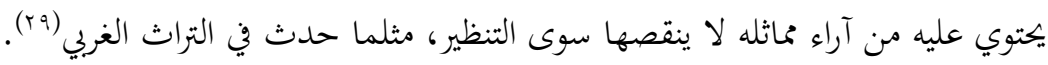

(1) إمام عبد الفتاح إمام :ارسطو والمرأة، مكتبة مدبولي، طبعة أولى، القاهرة 997 اصV

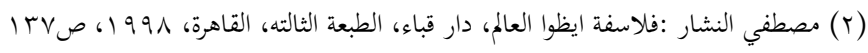

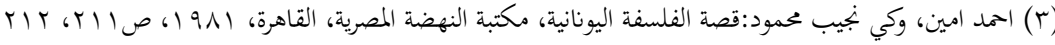

(₹) Susan. G. Bell: Women From The Greek To The French reduction, Stand ford university, press 19vr, $\mathrm{p}: 1 \mathrm{~V}$

$$
\text { V V (0) (مام عبد الفتاح إمام ، أرسطو و المر أه ، ص V) }
$$




$$
\text { r }
$$

كانت المرأة عند جون لوك مثلما كانت عند أفلاطون و عند اليونانيين عامة، فالمرأة لا تساوي شيئا على الإطلاق، حيث كانت ليبرالية لوك تمدف إلى الدفاع عن الرجل الفرد و حقوقه

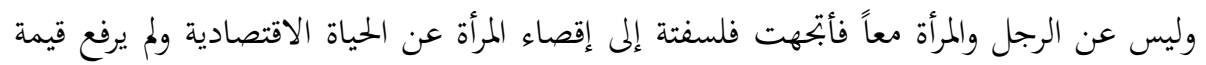

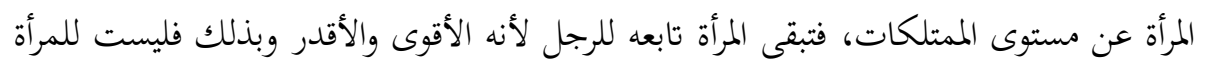

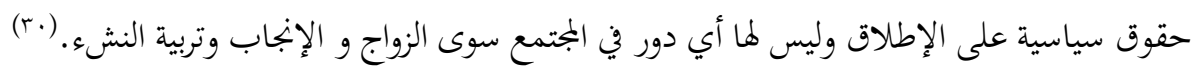

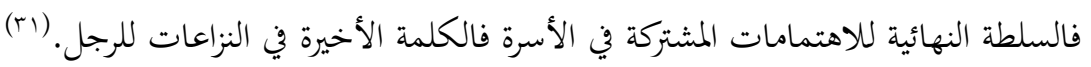

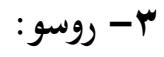

يرى روسو أن الدونية هي خاصية المرأة الأولى، فكوها أدنى من الرجل فذلك حكم طبيعي، رونا،

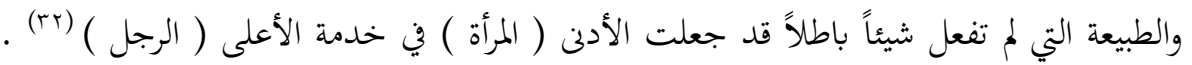

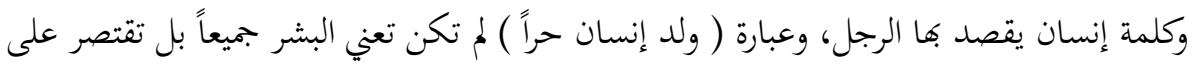

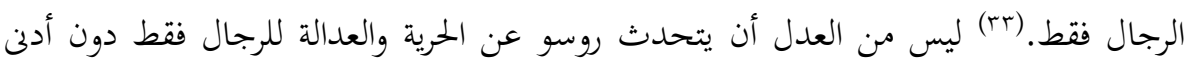

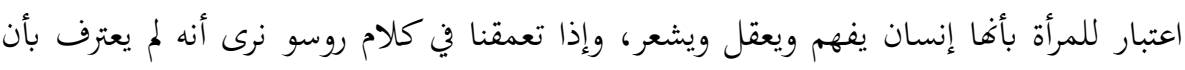

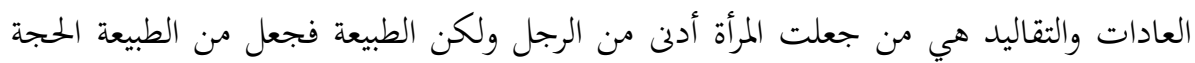

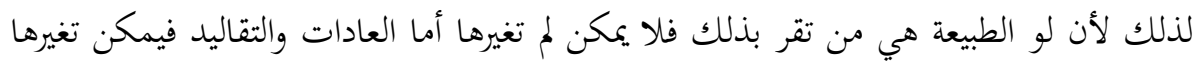
بطرق مختلفة.

تحدث روسو عن تربية المرأة وأهمية الاهتمام بالنساء في موضوع التربية لأها هي أساس

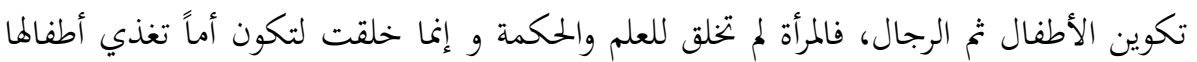

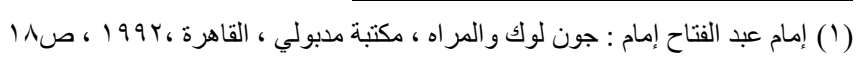

$(r)$ Nancy J Hirschmann and kristiem . Mcclure : feminist internetation of joun locke, the pennsy lvania state university, $r \cdots \vee, p: \varepsilon$

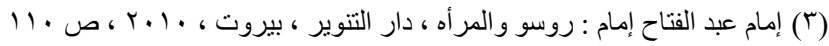

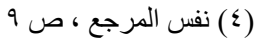


بلبنها.(«) فالطبيعة حرمت المرأة من القوة البدنية والعقليه ولكن في نفس الوقت وهبتها قدرات تساعد في إدارة شئون منزها.

كانت نظرية روسو للمرأة سيئه للغاية بل كانت رجعية على الرغم من دفاعه عن الحريه والعداله وحقوق الفقراء و دعوته للمساواة إلا أنه يناقض نفسه فهاجمهم وقال إفم أصل الفساد والاغيار الأخلاقي، فكان يتجاهل المرأة ولا يكمن أهميتها سوى الحفاظ على زوجها وأولادها والمحافظة على شرفها ـ فروسو لا يتحمس إلى تعليم المرأة إلا في أضيق الحدود لإداره شئون منزلما فتصبح أمرأة بسيطه ( جاريه مطيعه لسيدها ).

\section{-}

كان هيجل أيضاً ينكر فعلياً المساواة بين الرجل والمرأة، فالنساء لا يقمن بعمل مأجور في المجال العام، وفي الأسرة يكون الزوج هو رب الأسرة والمسئول بشكل أساسي عن رعاية إحتياجات

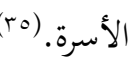

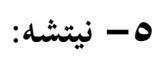

كانت المرأة في فلسفة نيتشه تحمل صفات العبيد والطاغيه في آن واحد، فلا تصلح إلا للطاعة. (rr) فيجب أن تخضع للرجل في كل شيء فيكون ولي نعمتها ويريد منها أن تنجب الأطفال وتربيهم بدون تعليم وبلدون فكر أو منهج. فكل هؤلاء الفلاسفة تأثرو بنظرة الفكر الأفلاطوي للمرأة، و تأثرو كذلك بروح عصرهم الذي كان قريب العهد بعصر الاقطاع والعصور الوسطي .

(0) جان جاك روسو : تربية الطفل من المهد إلى الرشد ، الجزء الخاص ، نقله للعببيه د/ نظمي لوقا ، تقديم الاستاذ احمد زكي محمد ، الشركه العربيه للنشر ، ص ع؟

(1) thom brooks : Hegl's philosophy of right, library of congress, r $, 1 r, p: 1 \leqslant r$

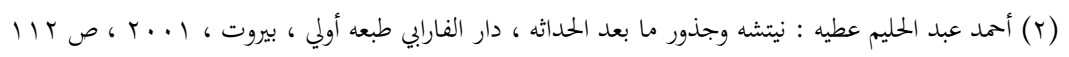




\section{تأثر جون ستيوارت مل بثقافة عصره

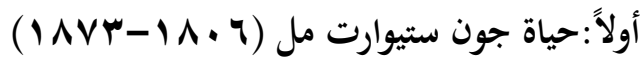

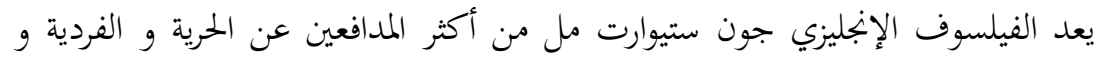

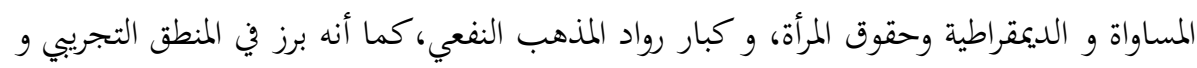

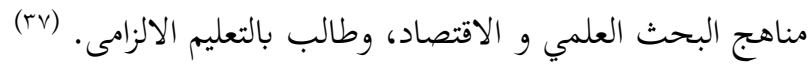

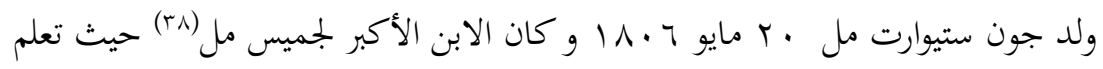

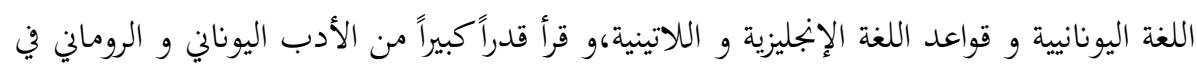

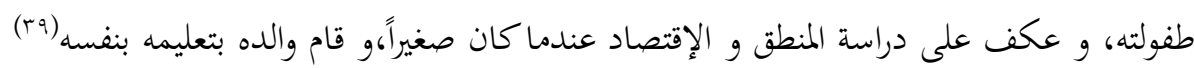

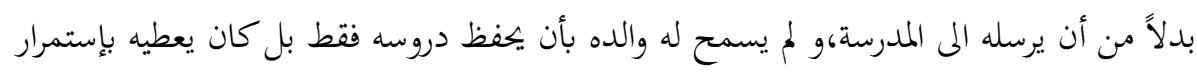

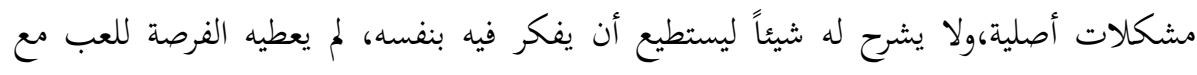

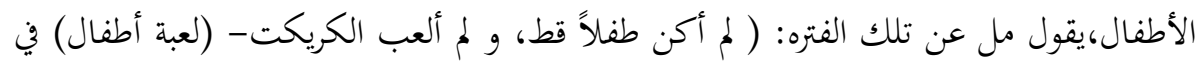
(ء.). حياتي)

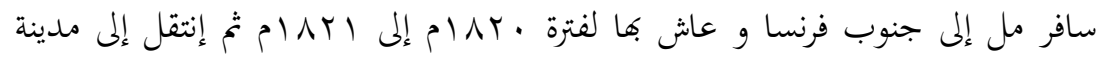

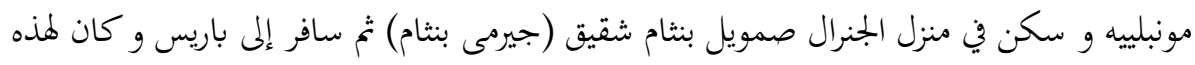

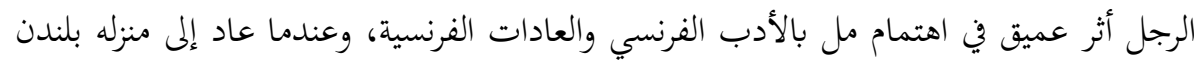

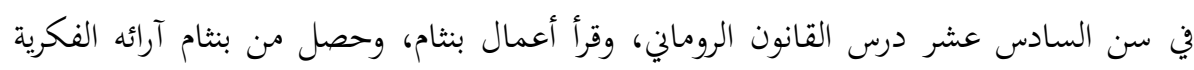

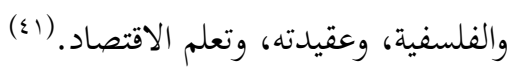

(1) فرديك كوبلستون،تاريخ الفلسفة ،ترجمة إمام عبد الفتاح إمام ،طبعة أولى ،المجلس الأعلى للثقافة ،القاهرة، ب . Y م.

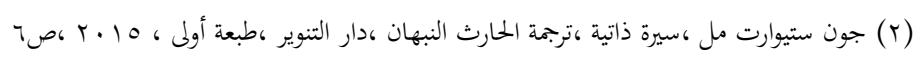
(r) وليم كلى رايت ، تاريخ الفلسفة الحديثة ،ترجمة محمود سيد احمد، ،قديم و مراجعة إمام عبد الفتاح إمام، طبعة اولى ،دار

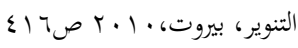

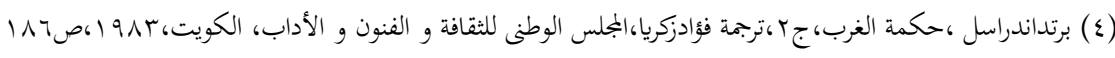

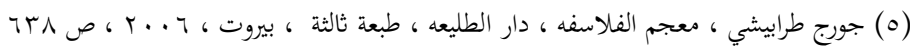


وعن حياته الوظيفية يقول مل في مايو r ب ا ا تقررت وظيفتي وتم تعيني في مكتب مفتش

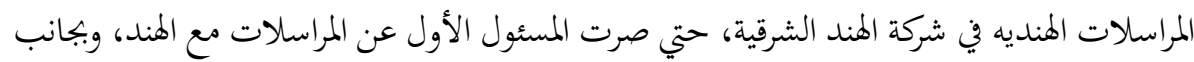

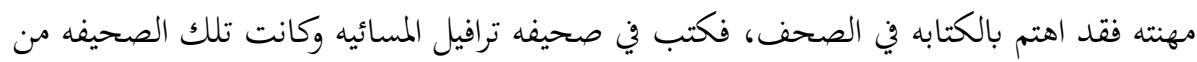

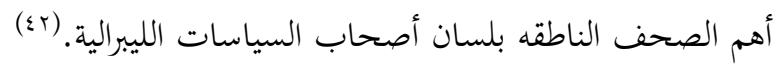

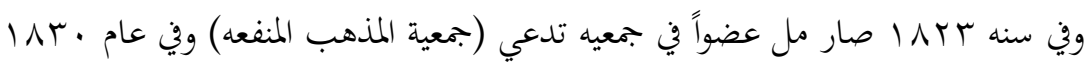

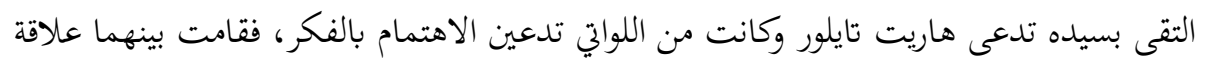

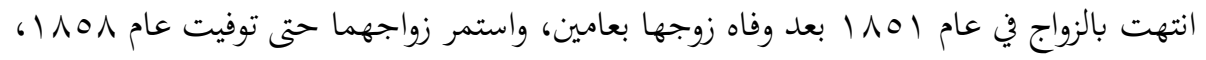

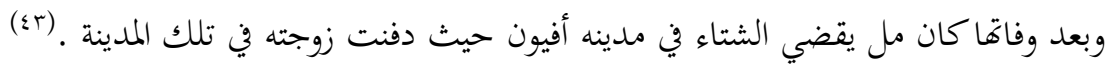

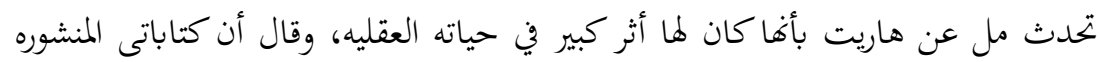

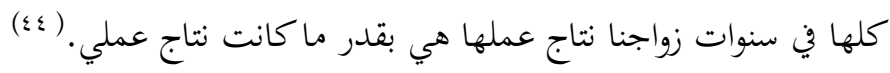

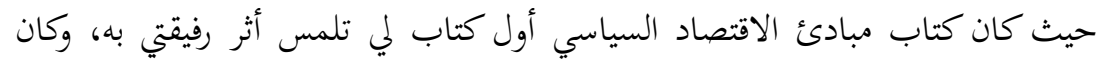

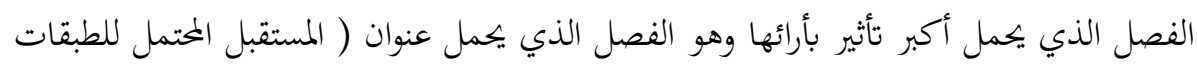

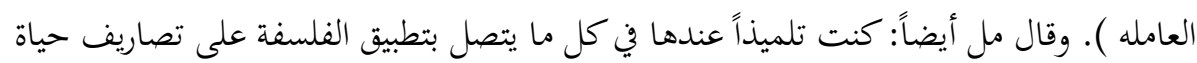

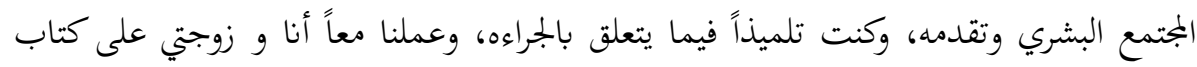

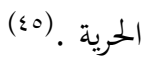

إن حياه جون ستيوارت مل في الفترة الأخيرة لم تقتصر على تقديم نظريات فلسفية بل تمثلت

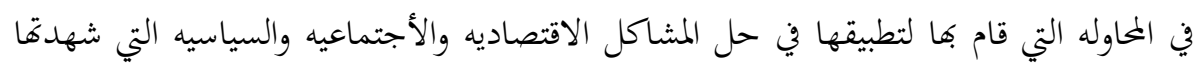
انجلترا في عصره، وهو ما جعله رشح نفسه للانتخابات البرلمانيه، ويفوز بمقعد في البرلمان لفتره (纟५) $(1 \wedge 71-1 \wedge 70)$

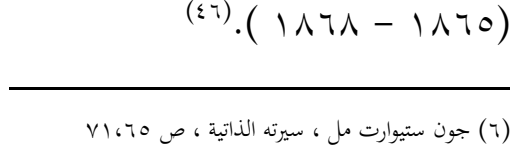

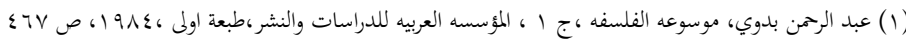

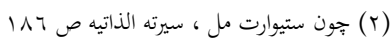

11 117 نفس المصدر، ص) (r)

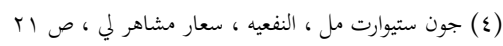


وكان رأي مل أن من حق النساء أن يكن متمثلات في البرلمان على قدم المساواة مع الرجال،

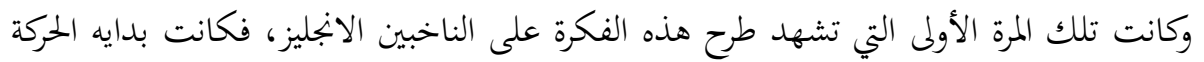

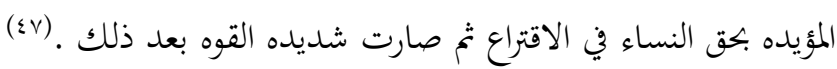

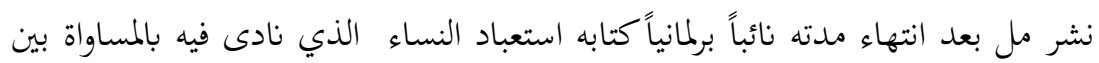

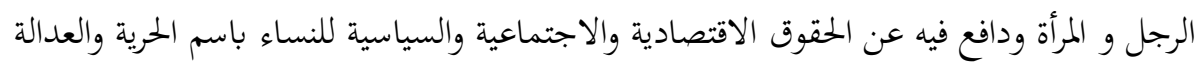

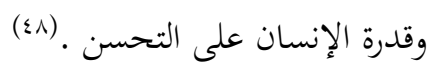
توفي جون ستيوارت مل عام س IVT وقامت ابنة زوجته هيلان تايلور بنشر السيرة الذاتية

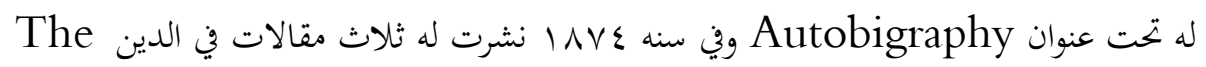
Essays on religion

$$
\text { ثانياً: مؤلفاته: }
$$

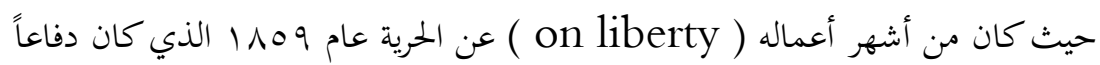

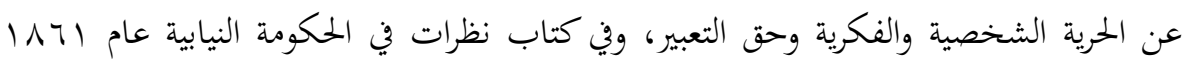
الذي نادى فيه المؤسسات (consideration represountative government)

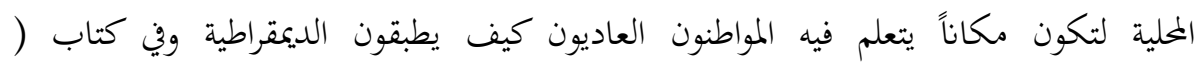
(utilitaranism (مذهب المنفعة ) rابمام أوضح جذور فلسفته الليبرالية، ومن أعماله

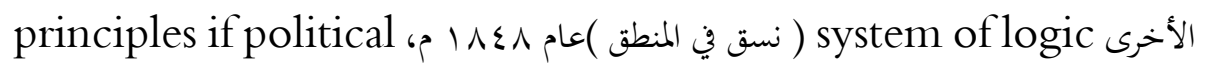
The subjection of مبادئ الاقتصاد السياسي ) عام 1 economy ( ) Women

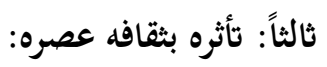
تأثر مل بفلسفه بنثام ( جيرمي بنثام ) الذي كان صديق والده، حيث تأثر بنثام بأفكار

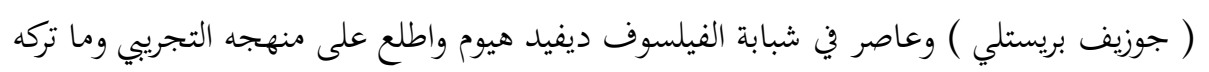

(0) جون ستيوارت مل ، سيرته الذاتيه ، ص rاب

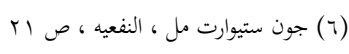

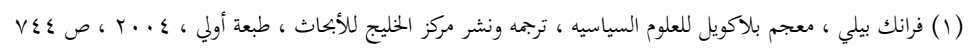


من تأثيرات على جميع الفلاسفة في أوروبا، في ظل هذه الشجرة الفلسفية عائش جون ستيوارت مل

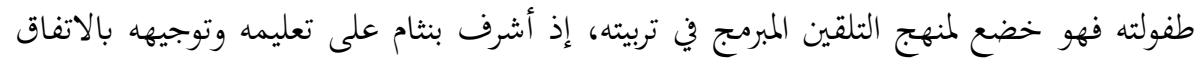

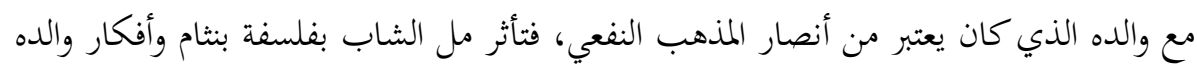

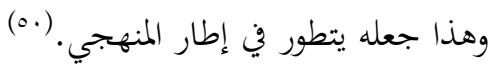
بعيداً عن التأثير الذي كان لوالده عليه، فإن مل تأثر بهاريت تايلور الذي كانت صديقته

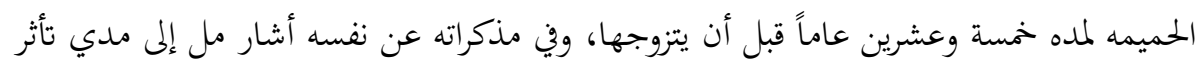

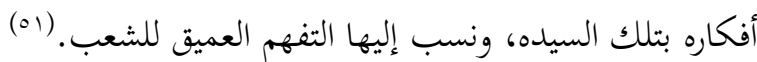

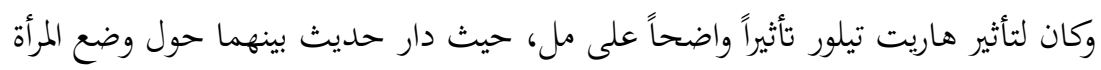

و ودورها

في المجتمع الأنجليزي، وتبادلا وجهات النظر وبمعت بينهما رؤية واحده وهي أن الوضع

$$
\text { الحالي للمرأة سئ للغايه. }
$$

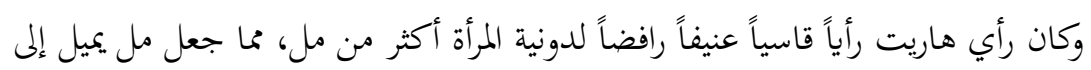

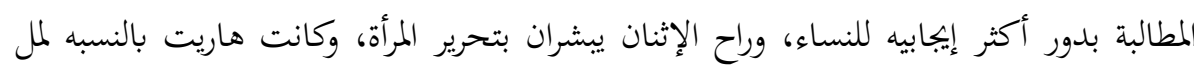

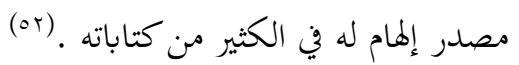

قام جون ستيوارت مل و زوجته هاريت بربط مسألة اضطهاد المرأة بقضية الحرية والمنفعة،

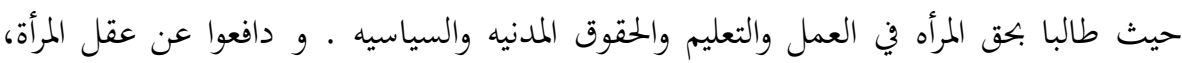
فالرجال ليسوا أكثر عقلانيه من النساء. كان لفكر جون ستيوارت مل تأثير على برتراند راسل أكبر الأثر في معظم كتاباته الفلسفيه،

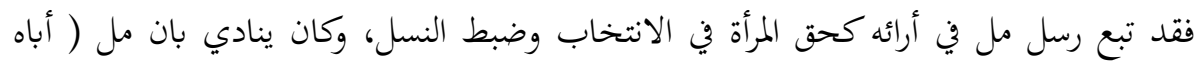

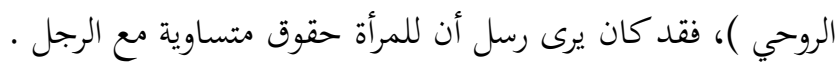

(r) جون ستيوارت مل : الحكومات البرمانيه ، نقله للعربيه إميل الغرري دار اليقظه العربيه ،المركز العربي للابحاث ودراسة

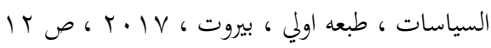

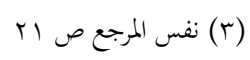

(1) جون ستيوارت مل : استعباد النساء ، ترجه : (مام عبد الفتاح امام ، ص 9 
يرى رسل متأثر بجو ستيوارت مل، أن طغيان الأكثرية في المجتمع الديمقراطي يشكل تمديداً

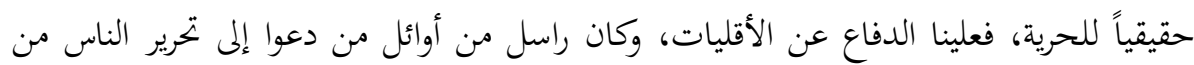

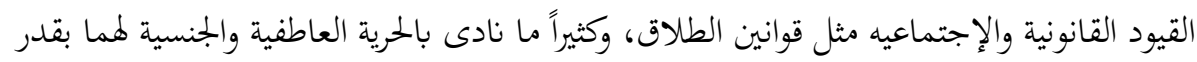

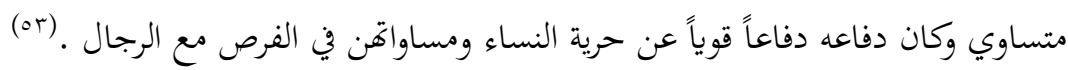

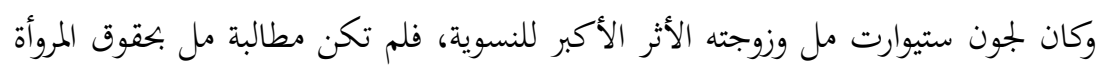

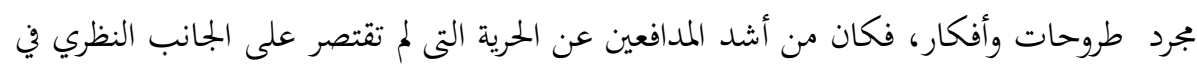

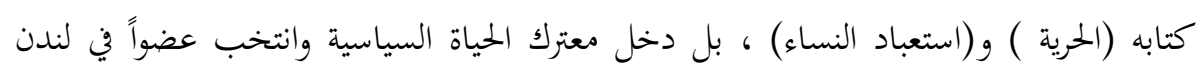

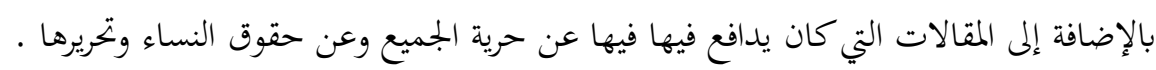

(r) بحموعة من الأكاديمن العرب الرابطة العربية لأكاديمية الفلسفة : الفلسفة والنسوية (في فضح ازدراء الحق الانثوى ونقضة والتمركز

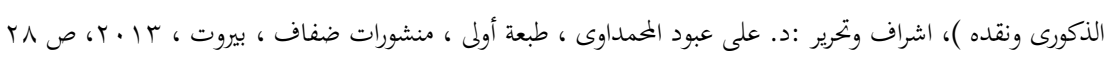




\section{المراجع}

1- إبراهيم (مفيده محمد): المرأة العربية والفكر الحديث، دار مجدلاوي للنشر والتوزيع، طبعه أولى،

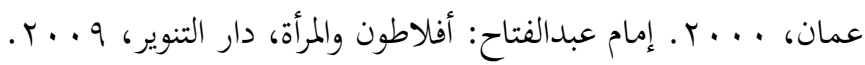

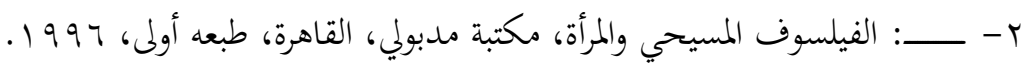

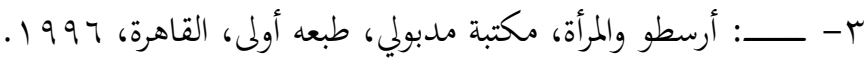

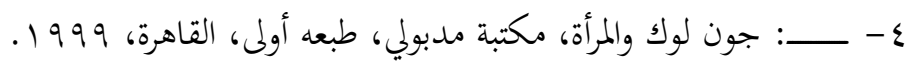

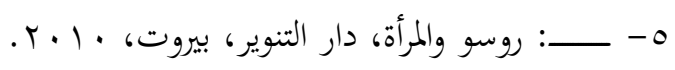

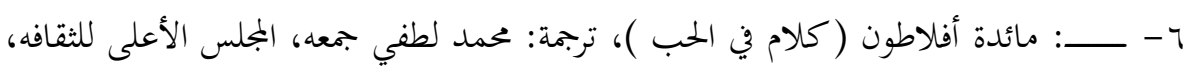

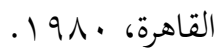

V- السروي (د.حمزه): المدينه الفاضله بين أفلاطون والفارابي، دار الكتبي، طبعه أولى، القاهرة،

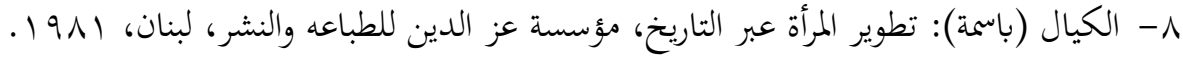

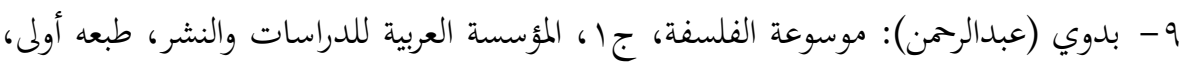
$.191 \varepsilon$

• 1- بيلي (فرانك): معجم بلاكويل للعلوم السياسيه، ترجمة ونشر مركز الخليج للأبحاث، طبعة

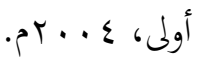

11- - ديورانت (ول ): قصة الحضارة، المجلد الأول، ترجمة زكي نجيب محمود ومحمد بدران،

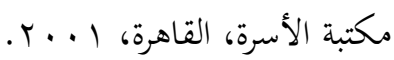

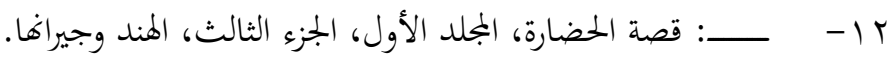

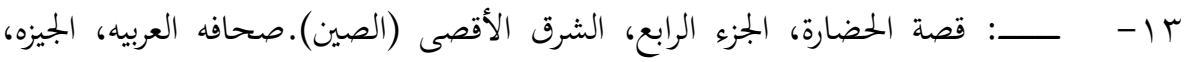
.$r \cdot 1 \Lambda$

ـ ا- - رايت (وليم كلي): تاريخ الفلسفه الحديثه، ترجمة محمد سيد أحمد، تقديم ومراجعة إمام

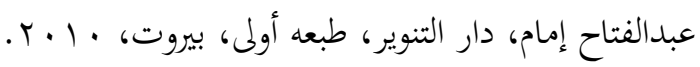

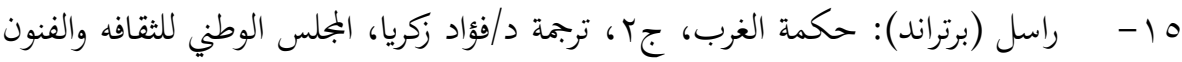
والأدب، الكويت، بره 19، بدون طبعه. 
ד ا - روسو (جان حاك): تربية الطفل من المهد إلى الرشد، الجزء الخامس، نقله للعربية د.نظمي لوقا، تقديم الأستائ احمد زكي محمد، الشركة العربية للنشر.

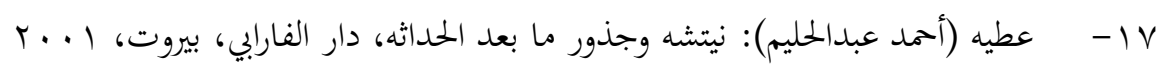

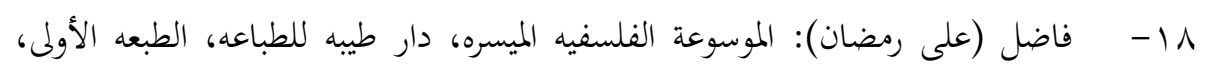
الجيزة.

9 ا - كوبلستون (فردريك): تاريخ الفلسفة، ترجمة إمام عبدالفتاح إمام، المجلد الأول (من اليونان

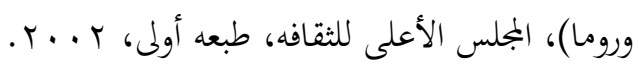

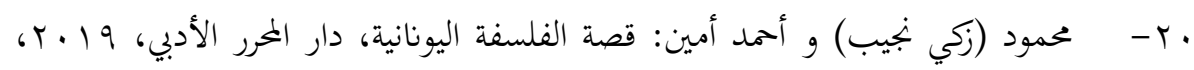

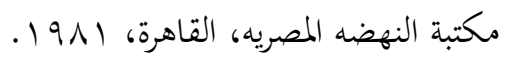

ا ب- مرحبا (د.محمد عبدالرحمن): الموسوعه الفلسفيه الشامله من الفلسفه اليونانيه إلى الفلسفه الإسلاميه، المجلد الأول، دار عويدات للنشر والطباعه، بيروت، V. . . . . .

T - مصطفى النشار: فلاسفة أيقظوا العالم، دار قباء، طبعة ثالثه، القاهرة، 19 19 بr- مل مل: حون سيتوارت مل: سيره ذاتيه، ترجمة الحارث النبهان، دار التنوير.

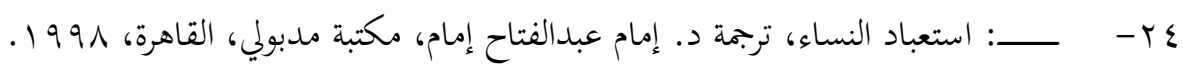

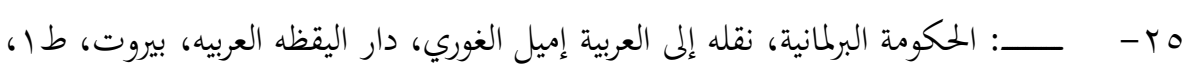
.$r \cdot 1 \mathrm{~V}$

ד ب- _ _ــــ النفعية، ترجمة: سعاد شاهرلي، مراجعة هيثم غالب التاهي، المنظمه العربيه للترجمه،

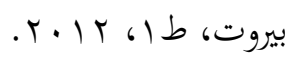

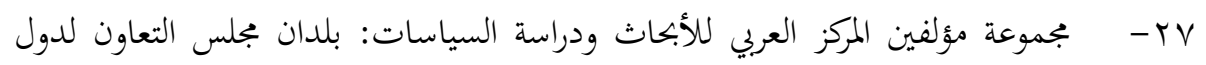

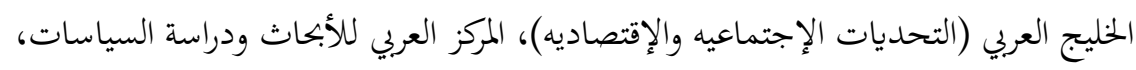

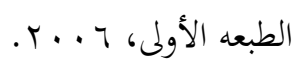

^ץ- نظير (وليم): المرأة في تاريخ مصر القديم، تقديم د. ياهور لبيب، م.د.محمد حماد، وكالة

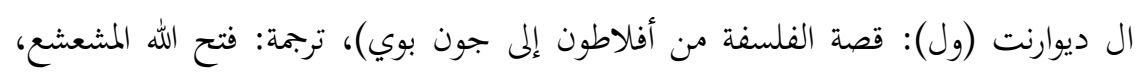

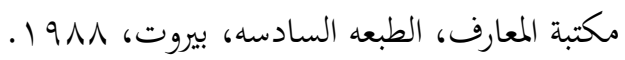




$$
\text { المراجع الاجنبية }
$$

1-Bell (susan.G): women from the greek to the French revdution, stand ford university, press, I $9 \mathrm{Vr}$

$r$ - Brooks (thom): hegl's philosophy of right, library of congress, $r \cdot 1 r$

r- Hrschmann (Nancy.j) and mcclure (kristiem): Feminist interpretation of john locke, the Pennsylvania state university, $r \cdots \vee$. 